\title{
Papillon-Lefèvre syndrome: clinical presentation and management options
}

This article was published in the following Dove Press journal:

Clinical, Cosmetic and Investigational Dentistry

15 July 2015

Number of times this article has been viewed

Basapogu Sreeramulu'

Naragani DVN Shyam²

Pilla Ajay'

Pathipaka Suman'

'Department of Prosthodontics, 2Department of Oral Pathology, Government Dental College and Hospital, Hyderabad, Telangana State, India

Video abstract

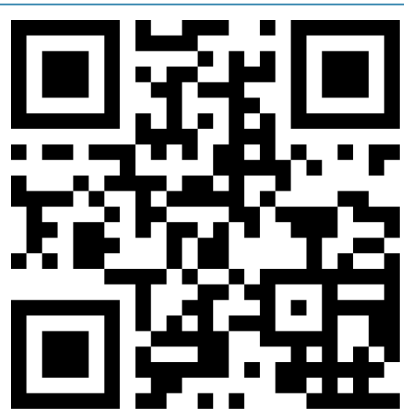

Point your SmartPhone at the code above. If you have a QR code reader the video abstract will appear. Or use: http://youtu.be/000yLpBXizg
Correspondence: Basapogu Sreeramulu Department of Prosthodontics, Government Dental College and Hospital, Afzalgunj, Hyderabad, Telangana State -500012 , India Email drsreeramulub@gmail.com
Abstract: Papillon-Lefèvre syndrome (PLS) is a rare autosomal recessive disorder, characterized by diffuse palmoplantar keratoderma and precocious aggressive periodontitis, leading to premature loss of deciduous and permanent dentition at a very young age. Various etiopathogenic factors are associated with the syndrome, like immunologic alterations, genetic mutations, and the role of bacteria. Dentists play a significant role in the diagnosis and management of PLS as there are characteristic manifestations like periodontal destruction at an early age and an early eruption of permanent teeth. Here, we are presenting an elaborate review of PLS, its etiopathogenesis, clinical presentation, and management options.

Keywords: deciduous and permanent dentition, modified complete dentures, palmoplantar keratoderma, periodontitis

\section{Introduction}

Papillon-Lefèvre syndrome (PLS) was first described by two French physicians, Papillon and Lefèvre, in France. ${ }^{1}$ It is an autosomal recessive inherited disorder of keratinization, ${ }^{2}$ characterized by redness, thickening of the soles and palms, and severe destructive periodontal disease affecting both primary and permanent teeth, caused by mutations in cathepsin $C$ (CTSC) gene. ${ }^{3,4}$ Other symptoms include hyperhidrosis, arachnodactyly, intracranial calcification, increased susceptibility to infections, and mental retardation. ${ }^{5,6}$ The pedigree study reveals the mode of inheritance of the disease. PLS is inherited as an autosomal recessive disorder and if both parents are carriers of the defective gene there is a $25 \%$ risk for their children to be affected. ${ }^{7}$ The incidence of PLS is one to four per million with no sex and racial predominance. Between two and four people per thousand are heterozygous for the PLS gene and therefore they become carriers of the disorder; this results in a population prevalence of one to four per million people..$^{7-9}$ Greater frequency of occurrence in consanguineous offspring has been noted in approximately one-third of the cases. ${ }^{10}$ The disease becomes apparent by 2-3 years of age as an oral manifestation affecting the deciduous teeth with periodontal involvement leading to premature exfoliation of the same teeth. As the permanent dentition erupts, the same sequence of events recur, leading to the early shedding of the permanent dentition. Approximately $20 \%-25 \%$ of PLS cases suffer from increased susceptibility to infections other than periodontitis; most of them show predisposition to mild skin infections such as furunculosis or pyodermas. Occasionally, severe infections such as liver abscess or pneumonia occurs. ${ }^{11}$

PLS is caused by genetic defect located on chromosome 11q14.1-q14.3, which involves mutations of the CTSC gene. ${ }^{12}$ Various studies in PLS patients have shown 
more than $90 \%$ reduction in CTSC activity with resultant reduced host response against bacteria. ${ }^{13,14}$ Despite these advances in characterizing the genetic basis of the syndrome, the pathogenic mechanisms leading to the periodontal involvement remain elusive. An impaired chemotactic and phagocytic function of polymorphonuclear leukocytes (PMNs) has been described in several studies. ${ }^{15-17}$

Reports from Celenligil et al and Góngora et al document decreased proportions of certain lymphocyte subpopulations. ${ }^{18,19}$ In contrast, a few other studies reported normal PMN chemotaxis and lymphocyte function in PLS. ${ }^{20,21}$ So, the available reports on immunological alterations in PLS patients do not provide any consistent findings. This has left unanswered the question of whether immunologic functions are impaired in PLS.

Subgingival plaque samples from periodontal pockets of PLS cases contain primarily Actinobacillus actinomycetemcomitans. ${ }^{22,23}$ Other suspected periodontal pathogens including Porphyromonas gingivalis, Fusobacterium nucleatum, Bacteroides forsythus, Treponema denticola, and Prevotella intermedia have also been implicated to play a role in PLS periodontal pathogenesis. ${ }^{24,25}$

\section{Etiology}

The etiology of PLS is not completely understood. Both sexes are equally affected with no racial predominance. Anatomic, microbial, and viral agents as well as host response are suspected causative factors. ${ }^{26,27}$

\section{Genetic aspects}

High incidence of PLS is seen in consanguineous marriages. ${ }^{28}$ The CTSC gene encodes a cysteine-lysosomal protease also known as dipeptidyl-peptidase I, which functions to remove dipeptides from the amino terminus of the protein substrate. It also has endopeptidase activity. The CTSC gene is expressed in epithelial regions commonly affected by PLS such as palms, soles, knees, and keratinized oral gingiva. It is also expressed at a high level in various immune cells including PMNs, macrophages, and their precursors. Several mutations have been reported in the CTSC gene in individuals from diverse ethnic groups. ${ }^{29}$

\section{Immunological aspects}

CTSC gene is involved in a wide variety of immune and inflammatory responses. It plays a vital role in activating serine proteinases expressed in the granules of bone marrow-derived cells from both the myeloid and lymphoid series. The serine proteinases play a major role in a variety of inflammatory and immune processes, including phagocytic destruction of bacteria and activation of phagocytic cells and T-lymphocytes. Therefore, deficiency of CTSC function will result in loss of immunological response, leading to liability of infection. Recent advances reported that the impairment of natural killer cell cytotoxic function is the first consistent immune dysfunction in PLS. This suggests that the impaired natural killer cell cytotoxicity might contribute to the pathogenesis of PLS-associated periodontitis. ${ }^{30}$ The loss of CTSC function and subsequent inactivity of neutrophil serine proteinases may cause deregulation of localized PMNs' response in inflamed periodontal tissues, leading to the severe tissue destruction in PLS. ${ }^{31,32}$

\section{Microbial aspects}

Neutrophil-function test in PLS showed reduced response to Staphylococcus spp. and A. actinomycetemcomitans. There is a hypothesis that herpes viruses together with pathogenic bacteria including A. actinomycetemcomitans and underlying host defense disorders participate in the development of PLS periodontitis. ${ }^{33}$ Existence of various virulence factors, such as leukotoxin, collagenase, endotoxin, epithelial toxins, and fibroblast-inhibiting factor, suggests that PLS is mediated bacteriologically. The serum from affected patients shows high immunoglobulin $\mathrm{G}$ titer against $A$. actinomycetemcomitans. Moreover, A. actinomycetemcomitans colonies were cultured in high percentages from the periodontal pocket samples. ${ }^{34}$

\section{Clinical presentation Oral features}

The major features of PLS consist of severe gingivostomatitis and periodontitis. Eruption of deciduous teeth occurs at expected ages in normal sequence with normal structure and form, although microdontia, root resorption, and incomplete root formation have been reported in some cases. ${ }^{35,36}$ During the 1st year after eruption of deciduous teeth, gingiva becomes inflamed, followed by rapid destruction of periodontium manifested by noticeable reddened and swollen gingiva, associated with extensive resorption of bone and deep periodontal pockets from which pus exudates in response to the slightest pressure. Mastication is very painful because of teeth mobility. Usually, fetid mouth odor is present. Tenderness of regional lymph nodes has also been observed. ${ }^{37}$ The characteristic oral manifestations are the looseness, hypermobility, drifting, migration, and exfoliation of teeth without signs of root resorption. Hence, premature loss of deciduous teeth occurs at the age 4-5 years and the child becomes completely edentulous with gingiva returning to 
its normal healthy status. But the cycle repeats as aggressive periodontitis after the eruption of permanent teeth or successor teeth. Most of the successor teeth are lost by early teen years (Figure 1); once the teeth are lost, the gingiva shows no further signs of periodontal changes and wisdom teeth are often spared. ${ }^{38}$ Both maxillary and mandibular alveolar ridges are highly resorbed resulting in reduced vertical dimension of occlusion and, hence, the patient will have characteristic "denture face" appearance. ${ }^{39}$

\section{Cutaneous or dermatological features}

Cutaneous lesions or skin lesions of PLS (keratoderma) are usually manifested simultaneously with oral manifestations between the ages of 6 months and 4 years, coinciding with eruption of deciduous teeth. At the beginning, thickening of the skin is present; later, skin lesions are well demarcated extending to thenar and hypothenar eminences of palms, to the Achilles tendon and external malleoli of feet (Figure 2). The dorsal surface of fingers and toes as well as the elbows, knees, legs, and thighs are less severely affected, and the trunk is rarely affected. Lesions may vary in colour, texture, and manifestation; they appear as white, brown, red, and scaly patches which undergo crustation, cracking, and deep fissuring (Figure 3). Skin lesions get aggravated during cold weather and patients experience pain when walking. Infection may superimpose the defective skin leading to formation of abscesses. Other findings are retardation of somatic development, follicular keratosis and hyperhidrosis (bromhidrosis), nail dystrophy, and calcification of falx cerebri and choroid plexus. ${ }^{40}$

\section{Histopathological features}

Usually, histopathologic features of PLS are nonspecific. The gingival epithelium may show hyperkeratosis, acanthosis,

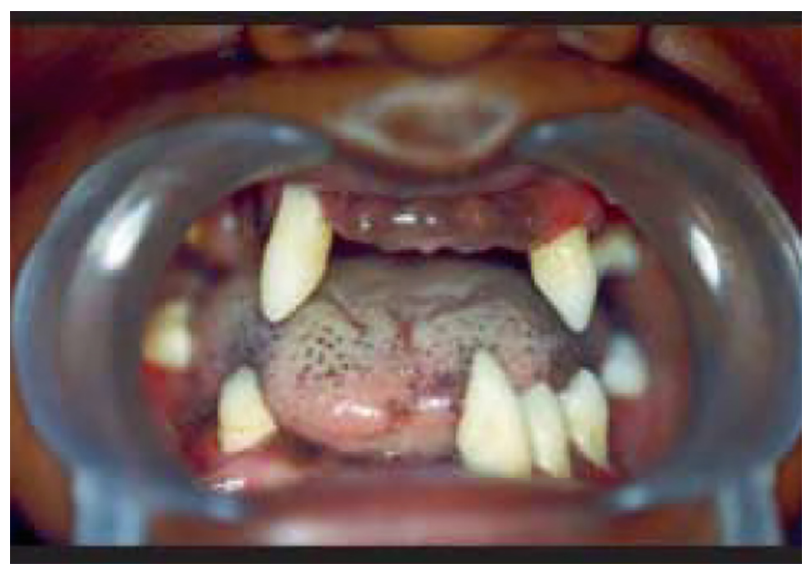

Figure I Intraoral photograph showing missing permanent teeth in upper and lower arch.
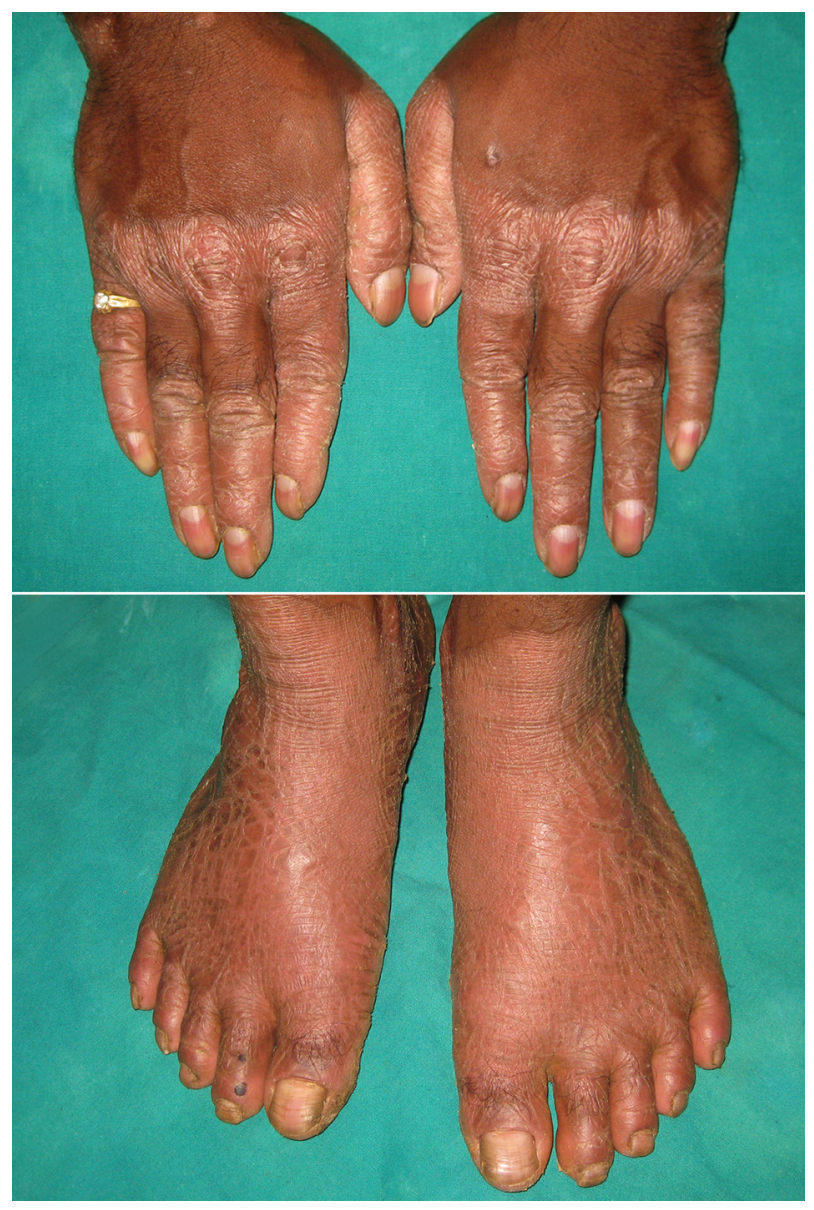

Figure 2 Hyperkeratosis of dorsal surfaces of the hands and feet.

hypergranulosis, occasional patches of parakeratosis, and psoriasiform hyperplasia. Exocytosis of inflammatory cells is seen in the periodontal pocket and the underlying connective tissue shows increased vascularity with a mixed inflammatory cell infiltrate consisting predominantly of

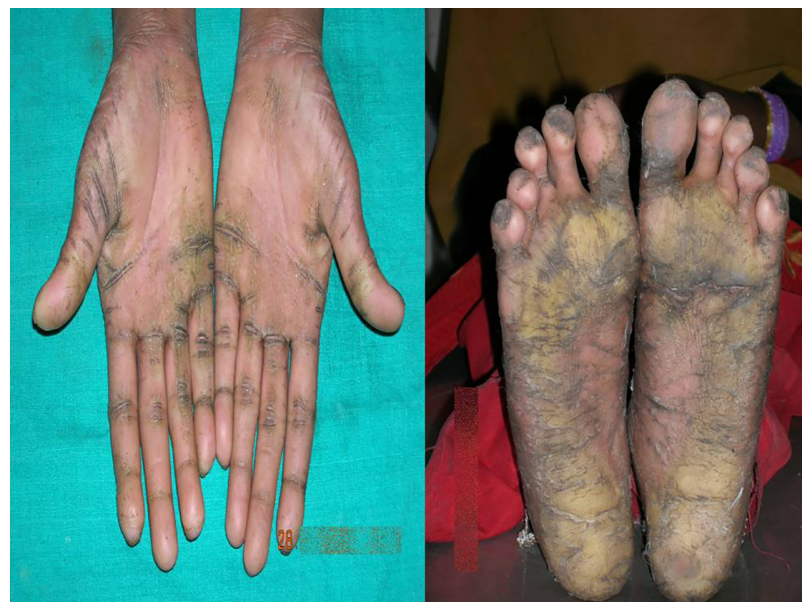

Figure 3 Hyperkeratosis, crustations, and deep fissuring involving palms and soles. 
polymorphonuclear neutrophils, lymphocytes, histiocytes, and plasma cells. ${ }^{41}$

Skin of palms expressed thickening of the epidermis, hypergranulosis, hyperkeratosis, and mild mononuclear cell infiltrate of papillary dermis.

\section{Radiographic features}

In the localized form, generally, vertical alveolar bone loss is seen around the incisors and first molars at around the age of puberty. The vertical pocket formation, with the bone loss often more extensive on one tooth than on an adjacent tooth, differs from the horizontal type of bone loss seen in chronic periodontitis; whereas in generalized form, bone loss may range from involvement of two teeth to a maximum number of teeth. ${ }^{42}$ Advanced cases reveal severe loss of alveolar bone and teeth appear to be floating in air (Figure 4). Unerupted teeth tend to develop normally in their bony crypts; in some cases, they assume an abnormal position and have incompletely formed roots. ${ }^{43,44}$

\section{Investigations}

The investigations that may be required for diagnosis are:

1. Hematological

2. Hormone assay

3. Height and weight calculation

4. Urine analysis

5. Alkaline phosphatase

6. Radiological investigations, such as orthopantomograph, intraoral periapical radiographs, and lateral cephalogram

7. Neutrophil function test

8. Conventional polymerase chain reaction for microbiological analysis.

Although the results of laboratory tests in patients with this syndrome are all essentially within normal limits, they are

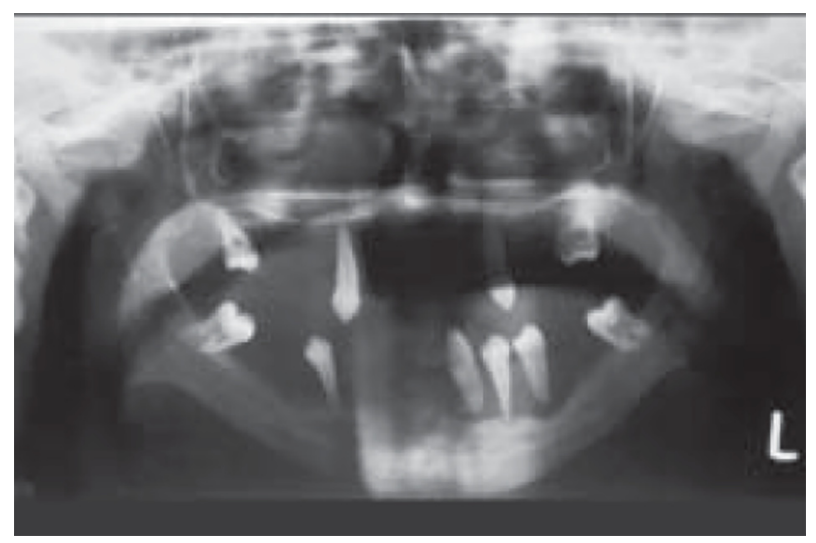

Figure 4 Orthopantomograph showing (floating in air) appearance of teeth. nonetheless particularly valuable in distinguishing this syndrome from other conditions causing gingival inflammation and early loss of the deciduous and/or permanent teeth.

\section{Differential diagnosis}

The differential diagnosis of this syndrome includes acrodynia, hypophosphatasia, and cyclic neutropenia. It differs from acrodynia or mercury poisoning by the presence of erythrocyanosis, insomnia, muscle pain, tachycardia, psychic disturbances, and teeth erupting prematurely with dystrophic enamel. The clinical features of knock-knee, bowing of the femur and the tibia, enlarged wrists, hypoplastic teeth, and increased amounts of phosphoethanolamine in the urine differentiates hypophosphatasia from this syndrome. In cyclic neutropenia, the palmoplantar hyperkeratosis is absent. The other conditions that can be included in the differential diagnosis are HowelEvans syndrome, Greither syndrome, and keratosis punctata. Even though all these entities are associated with palmoplantar hyperkeratosis, periodontopathy is not seen in them. ${ }^{45}$

\section{Management}

Management of PLS is challenging to the dentist as the prognosis is poor and the course of the disease is unpredictable. Prior to 1980 , tooth loss was considered to be an inevitable sequela to PLS. With the development of techniques for identifying periodontal pathogens, early treatment and compliance with prevention program are the major determinants for preserving permanent teeth in young patients.

A multidisciplinary approach involving a team of dermatologist, pediatrician, and dental surgeon team (periodontist, pedodontist, and prosthodontist) is important for overall care of the patient with PLS.

\section{Dental treatment}

The main aim of dental treatment in PLS is to eliminate the reservoir of causative organisms to control destruction of periodontium. ${ }^{46}$ Several treatment modalities have been suggested, such as: conventional periodontal treatment in the form of scaling and root planning; oral hygiene instructions and $0.2 \%$ chlorhexidine gluconate mouth rinses; and a course of antibiotic treatment therapy, which is suggested to control the active periodontitis in an effort to preserve the teeth and to prevent bacteremia and subsequent pyogenic liver abscess, which is a complication of PLS because of impairment of the immune system. The commonly used antibiotics are tetracycline and erythromycin, but in some cases, systemic antibiotics such as amoxicillin (20-50 mg/ $\mathrm{kg} / \mathrm{d})$ plus metronidazole $(15-35 \mathrm{mg} / \mathrm{kg} / \mathrm{d})$ in divided doses 8 hourly are used as an 
adjunctive treatment with conventional treatment. In some cases, amoxicillin and clavulanic acid was found effective. ${ }^{47}$

Extraction of deciduous teeth with poor prognosis and eradicating the periodontal pathogens creates a safe environment for eruption of permanent teeth. Teeth having deep periodontal pockets are treated by flap surgical procedures. To restore masticatory function, prosthetic approach is necessary.

The prosthetic approach is an age-specific treatment involving fabrication of partial or complete dentures initially. At an early age, during mixed dentition period, missing teeth are replaced with removable prosthesis (Figure 5). Smaller size and more translucent teeth are selected, giving space between the teeth that resembles deciduous dentition. After insertion of the removable prosthesis, regular follow-up of the patient has to be carried out. ${ }^{48}$ Rehabilitation of an edentulous PLS patient can be done with conventional complete dentures, modified complete dentures (Figure 6), implantsupported complete dentures, over dentures, or a combination of these; however, the final treatment will be based on chief complaint, patient's expectations, availability of supporting bone, and affordability of the treatment for the patient.

Dental implants are contraindicated in growing individuals since they act like submerged or ankylosed teeth, ${ }^{49}$ resulting in infra-positioning of implants. ${ }^{50}$ Implant-supported prostheses enhance the retention, support, and stability of prostheses. Osseo-integrated implants offer an alternative that

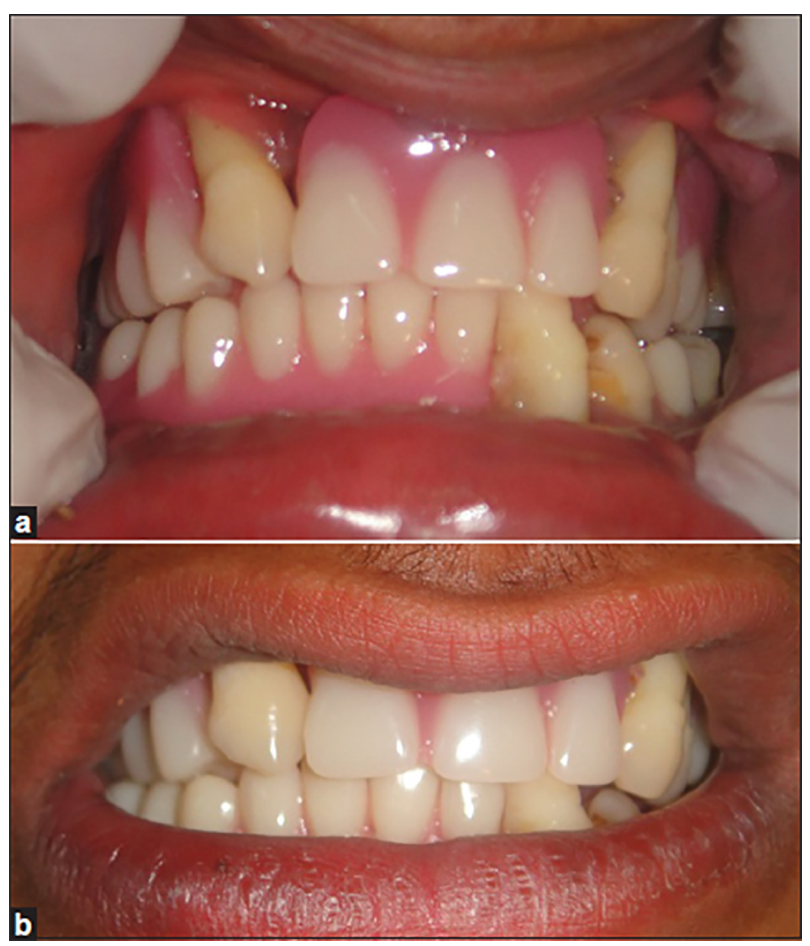

Figure 5 Prosthetic rehabilitation with removable partial dentures.

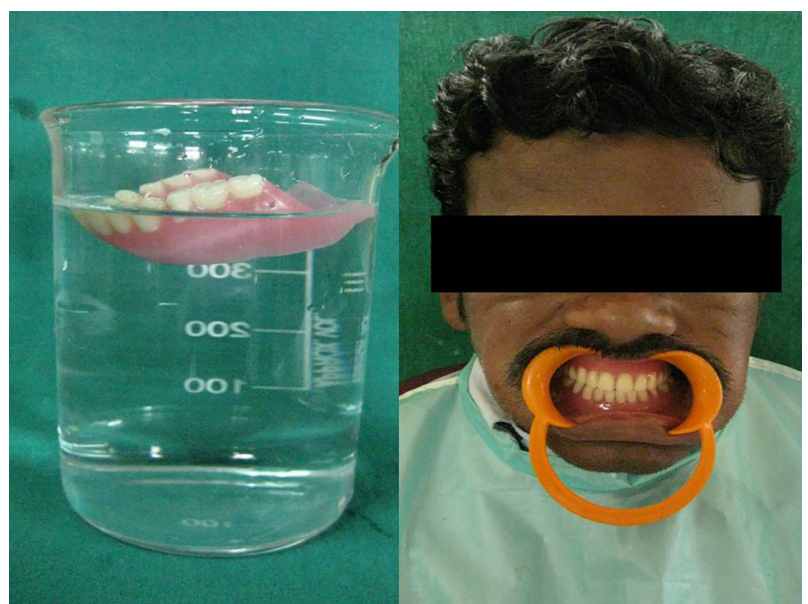

Figure 6 Prosthetic rehabilitation with modified removable complete denture.

will provide major improvements in the long-term prognosis for oral rehabilitation in PLS patients. ${ }^{51}$

Dermatological manifestations of PLS are usually treated with emollients, and salicylic acid and topical steroids may be added to enhance their effect. Oral retinoids such as acitretin, etretinate, and isotretinoin are proven to be beneficial in treating both dental and cutaneous lesions of PLS. ${ }^{52}$ Retinoid treatment is usually started at the time of eruption of successor teeth and is followed until the completion of the normal development process. ${ }^{53}$ These retinoids are vitamin A metabolites which are involved in the regulation of growth and differentiation of epithelial cells, and they are known to have a profound effect on keratinization by decreasing the total keratin content of keratinocytes. During recent years, systemic medication with synthetic retinoids has proven to possess a positive effect on cutaneous lesions in patients with PLS. ${ }^{54,55}$

Retinoids are also thought to influence inflammation by stimulating both humoral and cellular immunity. After 8 weeks of oral acitretin, there was a dramatic improvement with marked reduction of keratodermas. ${ }^{56}$

The adverse effects of retinoids include dryness of lips, mild pruritus, transient hair loss, elevated serum triglycerides and liver enzymes, hypervitaminosis A, teratogenicity, and liver toxicity.

In the long-term, therapy of keratosis with retinoids can lead to bone toxicity with resultant disturbances of growth in children, premature closure of epiphysis, and traumatic fractures. ${ }^{57}$ In the future, stem cell therapy can be expected to open up new modalities in dental treatment of such children.

\section{Conclusion}

PLS is a rare autosomal recessive disorder. It is important that dental professionals be familiar with the etiopathogenesis 
of PLS, as well as with PLS-specific dermatologic manifestations and periodontal involvement, to be able to identify the disease in its very early stages. Early diagnosis of PLSassociated periodontitis and institution of an appropriate periodontal/antimicrobial treatment regimen might improve the prognosis for the dentition. This should prevent or delay tooth loss and enhance early replacement of missing teeth for preservation of function and aesthetics. In conclusion, successful periodontal management of PLS patients remains challenging. However, as our understanding of the etiopathogenesis increases, it is hoped that successful treatment strategies will be developed. The prosthetic approach provides psychological and social benefit to the patient by restoring not only the function but also the aesthetic appearance.

\section{Disclosure}

The authors report no conflicts of interest in this work.

\section{References}

1. Sreeramulu B, Haragopal S, Shalini K, Sudha MD, Kiran G. The prosthodontic management of a young edentulous patient with the papillon lefevre syndrome-a rare case report. J Clin Diagn Res. 2012;6(10):1808-1811.

2. Ullbro C, Crossner CG, Nederfors T, Alfadley A, Thestrup-Pedersen K. Dermatologic and oral findings in a cohort of 47 patients with PapillonLefèvre syndrome. J Am Acad Dermatol. 2003;48:345-351.

3. Wani AA, Devkar N, Patole MS, Shouche YS. Description of two new cathepsin $\mathrm{C}$ gene mutations in patients with Papillon-Lefèvre syndrome. J Periodontol. 2006;77:233-237.

4. James WD, Berger T, Elston D. Andrews' Diseases of the Skin: Clinical Dermatology. 10th ed. Philadelphia: Saunders; 2006.

5. Hattab FN, Rawashdeh MA, Yassin OM, al-Momani AS, al-Ubosi M. Papillon-Lefèvre syndrome: a review of the literature and report of 4 cases. J Periodontol. 1995;66:413-420.

6. Sollecito TP, Sullivan KE, Pinto A, Steward J, Korostoff J. Systemic conditions associated with periodontits in childhood and adolescence. A review of diagnostic possibilities. Med Oral Patol Oral Cir Bucal. 2005;10:142-150. English, Spanish.

7. Hart TC, Shapira L. Papillon-Lefèvre syndrome. Periodontol 2000. 1994;6:88-100.

8. Haneke E. The Papillon-Lefèvre syndrome: keratosis palmoplantaris with periodontopathy. Report of a case and review of the cases in the literature. Hum Genet. 1979;51:1-35.

9. Cury VF, Costa JE, Gomez RS, Boson WL, Loures CG, De ML. A novel mutation of the cathepsin C gene in Papillon-Lefèvre syndrome. J Periodontol. 2002;73:307-312.

10. Khan FY, Jan SM, Mushtaq M. Papillon-Lefèvre syndrome: Case report and review of the literature. J Indian Soc Periodontol. 2012;16(2): 261-265.

11. Almuneef M, Al Khenaizan S, Al Ajaji S, Al Anazi A. Pyogenic liver abscess and Papillon-Lefèvre syndrome: not a rare association. Pediatrics. 2003;111:e85-e88.

12. Hart TC, Hart PS, Bowden DW, et al. Mutation of the cathepsin C gene are responsible for Papillon-Lefèvre syndrome. J Med Genet. 1999;36: 881-887.

13. Toomes C, James J, Wood AJ, et al. Loss-of-function mutations in the cathepsin $\mathrm{C}$ gene result in periodontal disease and palmoplantar keratosis. Nat Genet. 1999;23:421-424.
14. Oğuzkurt P, Tanyel FC, Büyükpamukçu N, Hiçsönmez A. Increased risk of liver abscess in children with Papillon-Lefevre syndrome. J Pediatr Surg. 1996;31:955-956.

15. Bullon P, Pascual A, Fernandez-Novoa MC, Borobio MV, Muniain MA, Camacho F. Late onset Papillon-Lefèvre syndrome? A chromosomic, neutrophil function and microbiological study. J Clin Periodontol. 1993;20:662-667.

16. Ghaffer KA, Zahran FM, Fahmy HM, Brown RS. Papillon-Lefèvre syndrome: neutrophil function in 15 cases from 4 families in Egypt. Oral Surg Oral Med Oral Pathol Oral Radiol Endod. 1999;88:320-325.

17. Liu R, Cao C, Meng H, Tang Z. Leukocyte function in 2 cases of Papillon-Lefèvre syndrome. J Clin Periodontol. 2000;27:69-73.

18. Celenligil H, Kansu E, Ruacan S, Eratalay K. Papillon- Lefèvre syndrome. Characterization of peripheral blood and gingival lymphocytes with monoclonal antibodies. J Clin Periodontol. 1992;19:392-397.

19. Góngora R, Corell A, Regueriro JR, Carasol M, Rodriguez-Gallego C, Paz-Artal. Peripheral blood reduction of memory (CD29+, CD45RO+, and "bright" CD2+ and LFA-1+) T lymphocytes in Papillon-Lefèvre syndrome. Hum Immunol. 1994;41:185-192.

20. Lyberg T. Immunological and metabolic studies in two siblings with Papillon-Lefèvre syndrome. J Periodontal Res. 1982;17:563-568.

21. Schroeder HE, Seger RA, Keller HU, Rateitschak-Plüss EM. Behavior of neutrophilic granulocytes in a case of Papillon-Lefèvre syndrome. J Clin Periodontol. 1983;10:618-635.

22. Ishikawa I, Umeda M, Laosrisin N. Clinical, bacteriological, and immunological examination and the treatment process of two PapillonLefèvre syndrome patients. J Periodontol. 1994;65:364-371.

23. Kleinfelder JW, Topoll HH, Preus HR, Müller RF, Lange DE, Böcker W. Microbiological and immunohistological findings in a patient with Papillon-Lefèvre syndrome. J Clin Periodontol. 1996;23:1032-1038.

24. Clerehugh V, Drucker DB, Seymour GJ, Bird PS. Microbiological and serological investigation of oral lesions in Papillon-Lefèvre syndrome. J Clin Pathol. 1996;49:255-257.

25. Velazco CH, Coelho C, Salzar F, Contreras A, Slots J, Pacheco JJ. Microbiological features of Papillon-Lefèvre syndrome periodontitis. J Clin Periodontol. 1999;26:622-627.

26. Drucker DB, Marshall R, Bird PS. Aetiology of Papillon LeFèvre syndrome. Anaerobe. 2001;7:151-158.

27. Cagli NA, Hakki SS, Dursun R, et al. Clinical, genetic, and biochemical findings in two siblings with Papillon-Lefèvre syndrome. J Periodontol. 2005;76:2322-2329.

28. Patel S, Davidson LE. Papillon-Lefèvre syndrome: a report of two cases. Int J Paediatr Dent. 2004;14:288-294.

29. Angel TA, Hsu S, Kornbleuth SI, Kornbleuth J, Kramer EM. Papillon-Lefevre syndrome: a case report of four affected siblings. J Am Acad Dermatol. 2002;46:S8-S10.

30. Lundgren T, Parhar RS, Renvert S, Tatakis DN. Impaired cytotoxicity in Papillon-Lefèvre syndrome. J Dent Res. 2005;84:414-417.

31. Ryu OH, Choi SJ, Firatli E, et al. Proteolysis of macrophage inflammatory protein-1 alpha isoforms LD78beta and LD78alpha by neutrophilderived serine proteases. J Biol Chem. 2005;280:17415-17421.

32. de Haar SF, Hiemstra PS, van Steenbergen MT, Everts V, Beertsen W. Role of polymorphonuclear leukocyte-derived serine proteinases in defense against Actinobacillus actinomycetemcomitans. Infect Immun. 2006;74:5284-5291.

33. Umeda M, Zhang VJ, Koseki T, Ishikawa I. [Clinical, bacteriological and immunological examination and treatment of two Papillon-Lefèvre syndrome patients]. Kokubyo Gakkai Zasshi. 1990;57(3):430-440. Japanese.

34. Albandar JM, Khattab R, Monem F, Barbuto SM, Paster BJ. The subgingival microbiota of Papillon-Lefèvre syndrome. J Periodontol. 2012;83:902-908.

35. Baghdady VS. Papillon-Lefevre syndrome: report of four cases. $A S D C$ $J$ Dent Child. 1982;49:147-150.

36. Fahmy MS. Papillon-Lefevre syndrome: Report of four cases in two families with a strong tie of consanguinity. A clinical, radiographic, haematological and genetic study. J Oral Med. 1987;42:263-268. 
37. Joshi HN, Dayal PK, Kansagra PJ. Papillon-Lefevre syndrome: report of case. ASDC J Dent Child. 1985;52(6):461-463.

38. Glenwright HD, Rock WP. Papillon-Lefevre syndrome: A discussion of aetiology and a case report. Br Dent J. 1990;168:27-29.

39. Kola MZ. Prosthodontic Management of Papillon-Lefevre syndrome with special focus on its characterization and diagnosis: A Clinical Report. Journal of Advanced Medical and Dental Sciences Research. 2014;2(4):97-104.

40. Pareek SS, Al-Aska AK. Papillon-Lefevre syndrome. A report of six cases in one family. Int J Dermatol. 1986;25:638-641.

41. Shah J, Goel S. Papillon-Lefèvre syndrome: two case reports. Indian J Dent Res. 2007;18:210-213.

42. Rajendran R, Sivapathasundharam B, editors. Diseases of the periodontium. In: Shafer's text book of oral pathology. 7th ed. New Delhi: Elsevier; 2012:411.

43. Munford AG. Papillon-Lefevre syndrome: report of two cases in the same family. J Am Dent Assoc. 1976;93:121-124.

44. Lu HK, Lin CT, Kwan HW. Treatment of a patient with Papillon-Lefèvre syndrome. A case report. J Periodontol. 1987;58:789-793.

45. Nagaveni NB, Suma R, Shashikiran ND, Subba Reddy VV. The Papillon-Lefevre syndrome: Report of two cases in the same family. J Indian Soc Pedod Prev Dent. 2008;26:78-81.

46. Dhanrajani PJ. Papillon-Lefevre syndrome: clinical presentation and a brief review. Oral Surg Oral Med Oral Pathol Oral Radiol Endod. 2009;108:e1-e7.

47. Kellum RE. Papillon-Lefèvre syndrome in four siblings treated with Etretinate. A nine-year evaluation. Int J Dermatol. 1989;28:605-608.

48. Jain V, Gupta R, Prakash H. Prosthodonti rehabilitation in PapillonLefevre syndrome: a case report. J Indian Soc Pedod Prev Dent. 2005; 23(2):96-98.
49. Oesterle LJ, Cronin RJ Jr, Ranly DM. Maxillary implants and the growing patient. Int J Oral Maxillofac Implants. 1993;8:377-387.

50. Brugnolo E, Mazzocco C, Cordioll G, Majzoub Z. Clinical and radiographic findings following placement of single-tooth implants in young patients - case reports. Int J Periodontics Restorative Dent. 1996;16: 421-433.

51. Adell R, Eriksson B, Lekholm U, Brånemark PI, Jemt T. Long-term follow-up study of osseointegrated implants in the treatment of totally edentulous jaws. Int J Oral Maxillofac Implants. 1990;5:347-359.

52. Ullbro C, Brown A, Twetman S. Preventive periodontal regimen in Papillon-Lefèvre syndrome. Pediatr Dent. 2005;27:226-232.

53. Al-Khenaizan S. Papillon-Lefèvre syndrome: the response to Acitretin. Int J Dermatol. 2002;41:938-941.

54. Singh R, Nor M, Ghazali W. Atypical Papiilon-Lefèvre syndrome: keratosis palmoplantaris with periodontopathy. Int J Dermatol. 1993;32: $450-452$.

55. Berman R, Friedman-Birnbaum R. Papillon-Lefèvre syndrome: a study of the long-term clinical course of recurrent pyogenic infections and the effects of etretinate treatment. Br J Dermatol. 1988;119:731-736.

56. Lundgren T, Crossner CG, Twetman S, Ullbro C. Systemic retinoid medication and periodontal health in patients with Papillon-Lefevre syndrome. J Clin Periodontol. 1996;23(3 Pt 1):176-179.

57. Prendiville J, Bingham EA, Burrows D. Premature epiphyseal closure a complication of etretinate therapy in children. J Am Acad Dermatol. 1986;15:1259-1262.
Clinical, Cosmetic and Investigational Dentistry

\section{Publish your work in this journal}

Clinical, Cosmetic and Investigational Dentistry is an international, peer-reviewed, open access, online journal focusing on the latest clinical and experimental research in dentistry with specific emphasis on cosmetic interventions. Innovative developments in dental materials, techniques and devices that improve outcomes and patient satisfaction

\section{Dovepress}

and preference will be highlighted. The manuscript management system is completely online and includes a very quick and fair peerreview system, which is all easy to use. Visit http://www.dovepress. com/testimonials.php to read real quotes from published authors. 